CDD: 142.3

\title{
UMA NOTA SOBRE A LÓGICA FORMAL DE KANT
}

\author{
PEDRO SANTOS
}

Universidade Federal De São Paulo

Estrada do Caminho Velho,333

Bairro dos Pimentas

07252-312 GUARULHOS - SP

BRASIL

pedromrs@gmail.com

Received: 30.06.20II; Revised: 02.II.20II; Accepted: 09.02.2012

Resumo: $\mathrm{O}$ artigo apresenta um problema que surge da combinação da teoria kantiana dos juízos analíticos com a sua adesão oficial à silogística. Argumenta-se em seguida que o problema só pode ser inteiramente solucionado pelo reconhecimento de que a lógica com a qual Kant de fato operava não é consistente nem com a silogística, nem com a lógica clássica, consistindo, de fato, em uma espécie de lógica inclusiva.

Palavra-chave: Kant. Lógica. Silogística. Analiticidade. Universalidade.

\section{A NOTE ON KANT'S FORMAL LOGIC}

\begin{abstract}
The paper presents a problem arising from Kant's theory of analytic judgments in conjunction with his official allegiance to the syllogistic. It is then argued that this problem can only be solved by the acknowledgement that the logic with which Kant operated was consistent neither the syllogistic nor with classical logic, consisting, in effect, in a species of inclusive logic.
\end{abstract}

Key-words: Kant. Logic. Syllogistic. Analyticity. Universality.

Manuscrito - Rev. Int. Fil., Campinas, v. 35, n. 1, p. 99-113, jan.-jun. 2012. 
Dentre as muitas teses que podem ser extraídas da Crítica da Razão Pura (CRP) de Kant, uma das mais influentes é, sem dúvida, aquela segundo a qual a mera reflexão acerca de um conceito pode revelar condições que uma coisa precisa satisfazer para cair sob ele; mas não se algo de fato cai sob o conceito. Na terminologia kantiana, a realidade objetiva de um conceito não pode ser estabelecida de maneira analítica. Desse modo, exceção feita às "categorias" ou "conceitos puros do entendimento" (cuja realidade objetiva é sintética a prior), pode-se dizer que, para Kant, a realidade objetiva de um conceito não pode ser conhecida a priori. Estranhamente, no entanto, há um argumento bastante simples que, partindo de premissas aparentemente kantianas, prova que a realidade objetiva de qualquer conceito pode ser conhecida $a$ priori.

O argumento é o seguinte:

P1) Quando um conceito $G$ está contido em um conceito $F$, a proposição Todo Fé $G$ é analítica.

P2) Toda proposição analítica é cognoscível a priori.

P3) Para quaisquer conceitos $F$ e $G$, a proposição Todo $F$ é $G$ implica logicamente a proposição Algum Fé G.

P4) $\mathrm{O}$ que se segue logicamente de algo cognoscível a priori também é cognoscível a priori.

P5) Para quaisquer conceitos $F$ e $G$, a proposição Algum $F$ é $G$ implica logicamente as proposições Existe um $F$ e Existe um $G$.

P6) Para qualquer conceito $G$ existe um conceito $F$ tal que $G$ está contido em $F$

$\therefore$ Para qualquer conceito $G$, a proposição Existe um $G$ é cognoscível a priori.

Que a conclusão realmente se segue das premissas pode se facilmente verificado: de P1 e P6 segue-se que para todo conceito $G$ existe um conceito $F$ tal que a proposição Todo $F$ é $G$ é analítica. Disso 
nós concluímos, por P2, que para todo conceito $G$ existe um conceito $F$ tal que a proposição Todo $F$ é $G$ é cognoscível a priori. Segue-se, então, por $\mathrm{P} 3$ e P4, que para todo conceito $G$ existe um conceito $F$ tal que a proposição Algum $F$ é $G$ é cognoscível a priori. A conclusão agora se segue por P4 e P5.

Argumentos mais fracos podem ser obtidos substituindo-se P6 por uma premissa que afirme que um conceito determinado está contido em outro. Por exemplo, podemos substituir P6 por

P6*) O conceito extensão está contido no conceito corpo,

e concluir que a proposição Existe algo extenso é cognoscível a priori. Podemos também abandonar P1) e substituir P6) pela atribuição direta de analiticidade a algum juízo.

Do ponto de vista moderno, esses argumentos não apresentam grandes dificuldades. A implicação expressa por P3 simplesmente não resulta válida se as formas em questão forem traduzidas da maneira usual para a linguagem do cálculo de predicados clássico. Essa solução, contudo, não está em princípio disponível para Kant, cuja adesão oficial à silogística está fora de dúvida. De fato, como veremos na seção seguinte, P1-P6 podem todas ser plausivelmente atribuídas a Kant. Por fim, na seção III, tentarei extrair as lições desse problema para a interpretação (ou reconstrução) de Kant, em especial de sua lógica formal.

\section{II}

P1 é uma conseqüência imediata da definição de juízo analítico contida na CRP. Kant diz:

Em todos os juízos, nos quais se pensa a relação entre um sujeito e um predicado (apenas considero os juízos afirmativos, porque é fácil depois a aplicação aos negativos), esta relação é possível de dois modos. Ou o predicado $B$ pertence ao sujeito $A$ como algo que está contido (implicitamente) nesse conceito $A$, ou $B$ está totalmente fora

Manuscrito - Rev. Int. Fil., Campinas, v. 35, n. 1, p. 99-113, jan.-jun. 2012. 
do conceito $A$, embora em ligação com ele. No primeiro caso chamo analítico ao juízo, no segundo sintético. (Kant, CRP, B10)

Note que essa definição gera um problema adicional: como Kant não menciona nenhuma restrição quanto às formas judicativas que ele tem em mente, poderíamos supor que era sua intenção incluí-las todas, em particular todas as formas categóricas. Mas, se fosse assim, para qualquer conceito $G$ contido em um conceito $F$, a proposição Algum $F$ é $G$ seria analítica, e o mesmo problema se seguiria de maneira ainda mais direta. Mas talvez aqui possamos supor que Kant estivesse implicitamente limitando o âmbito de sua definição à forma afirmativa universal. A aparente ausência de qualquer exemplo de um juízo analítico particular na CRP dá algum apoio a essa interpretação.

Quanto às formas negativas, e aplicando a mesma restrição à forma universal aplicada acima, teríamos que um juízo negativo universal Nenbum F é $G$ é analítico quando o conceito $G$ está excluído (implicitamente) do conceito $F$, ou algo desse gênero. Por exemplo, assumindo que o conceito alma inclui o conceito imaterial, a proposição Nenhuma alma é material seria analítica. Um problema análogo então se seguiria, já que na silogística a forma negativa universal implica logicamente a forma negativa particular, que parece ter força existencial. Note que nesse caso poderíamos supor que Kant tinha em mente a interpretação da forma negativa particular proposta por Ockham, de acordo com a qual, se numa proposição desse tipo o termo sujeito é vazio, a proposição é verdadeira. Essa interpretação equivale a tomar a forma particular negativa como a negação proposicional da forma afirmativa universal. Assumindo a força existencial da forma afirmativa universal, o que equivale a interpretar Todo $F$ é $G$ como $(\forall x(F x \rightarrow G x)$ $\wedge \exists x F x)$, a interpretação de Ockham implica que a forma particular negativa será verdadeira sse ou bem algum $F$ não for $G$, ou bem se nada for $F$. Ockham se referia a essas alternativas como as duas possíveis "causas da verdade" das proposições desse tipo. (Ver, a esse respeito, Church (1965), Parsons (2006) e Santos (2008)). Não tenho conhecimento de nenhuma evidência de que Kant estivesse ciente dessa 
possibilidade. De todo modo, a adoção da interpretação de Ockham não livra Kant do problema inicial, uma vez que essa interpretação obviamente valida a inferência por subalternação.

Alguém poderia tentar bloquear o argumento insistindo que nós levássemos em consideração apenas a caracterização da analiticidade em termos do princípio de contradição. Essa tentativa falharia por, no mínimo, três razões. Em primeiro lugar, a idéia é completamente sem força contra as formas mais fracas (mais igualmente paradoxais) do argumento, mencionadas acima, na medida em que ela passa por sobre qualquer caracterização geral de analiticidade, indo direto a instâncias particulares. Em segundo lugar, a noção fundamental de analiticidade para Kant é claramente aquela formulada em termos de conceitos. Nos Prolegômenos a Toda Metafísica Futura (PMF) Kant afirma:

Todo juízo analítico repousa inteiramente sobre o princípio de contradição (...). Pois uma vez que o predicado de um juízo analítico afirmativo já está de antemão pensado no conceito do sujeito, ele não pode ser negado daquele sujeito sem contradição. (PMF, $₫ 2$, (b), grifo meu).

Por fim, um argumento análogo pode ser construído com base nessa segunda caracterização. Para tanto basta substituir P1 pela caracterização alternativa e P6 pela afirmação de que para todo conceito $F$ há um conceito $G$ que não pode ser negado de $F$ sem contradição.

P2 pode ser igualmente extraída da Introdução da CRP. Em um juízo analítico, diz Kant,

(...) não preciso sair de meu conceito para formar o juízo e, por conseguinte, não careço do testemunho da experiência. Que um corpo seja extenso é uma proposição que se verifica a priori. (CRP, B12)

Quem quiser permanecer o mais próximo possível da letra do texto kantiano pode substituir "cognoscível" por "verificável" no argumento da seção I. Não penso que essa modificação faça qualquer diferença. Note, de passagem, que no trecho acima Kant formula seu 
exemplo padrão de juízo analítico com o artigo indefinido 'um', mas aparentemente com a intenção de expressar um juízo universal. Mais adiante veremos um exemplo importante dessa prática.

P3 não é nada além do princípio aristotélico de inferência por subalternação. Seria de se esperar que Kant aceitasse P3 em vista, por exemplo, da célebre passagem em que ele declara que, a não ser por questões de elegância na apresentação, a lógica encontra-se, desde Aristóteles, "acabada e perfeita, tanto quanto se nos pode afigurar". ${ }^{1} \mathrm{E}$, de fato, embora o conteúdo exposto por Kant em sua Lógica incorpore elementos da tradição peripatética posterior a Aristóteles, bem como elementos da lógica estóica, sua adesão oficial aos fundamentos da silogística é, de fato, inquestionável. No \#46 da Lógica, Kant afirma a validade do princípio de inferência por subalternação, e em \#53 das regras de conversão, em particular da conversão por acidente da forma afirmativa universal, i.e., da regra que afirma a validade de inferir Algum $G$ é F de Todo Fé G. Assim, é evidente que P3 é, ao menos oficialmente, aceita por Kant. Voltaremos mais adiante a esse ponto.

Que Kant aceitaria P4 pode ser inferido da passagem abaixo, onde ele está preocupado em estabelecer critérios seguros para a distinção entre um conhecimento puro e um empírico.

Em primeiro lugar, se encontrarmos uma proposição que apenas se possa pensar como necessária, estamos em presença de um juízo a priori; se, além disso, essa proposição não for derivada de nenhuma outra, que por seu turno tenha o valor de uma proposição necessária, então é absolutamente a priori. (CRP, B3)

É natural concluir que para Kant há proposições que são conhecidas a priori não imediatamente, mas por intermédio de uma derivação a partir de outras proposições a priori. Mas se isso é assim, é necessário que ele esteja vendo a "derivação" em questão como preservando a aprioricidade do ponto (ou pontos) de partida. Mas mesmo que não houvesse uma base textual para atribuir P4 a Kant,

\footnotetext{
${ }^{1}$ CRP, B VIII
}

Manuscrito - Rev. Int. Fil., Campinas, v. 35, n. 1, p. 99-113, jan.-jun. 2012. 
tampouco haveria qualquer razão para duvidar que Kant a aceitaria. Pois se as leis da lógica não são a priori, seguramente nada o é, e, portanto, ao obter, por meio de uma lei lógica, uma proposição a partir de uma outra que se conhece a priori, não há seguramente qualquer espaço para a intromissão de algo empírico.

P5 é uma conseqüência da maneira usual de compreender as condições de verdade de um juízo categórico particular. Pois para que o predicado se aplique a "algo do sujeito", como dizia Aristóteles, é preciso que haja "algo do sujeito", isto é, que o sujeito não seja vazio. ${ }^{2}$ Kant parece estar de acordo:

\footnotetext{
No juízo universal, a esfera de um conceito se vê inteiramente compreendida no interior da esfera de um outro conceito; no particular, uma parte do primeiro vê-se compreendida sob a esfera do outro ... (Log. \#21)
}

Se entendermos por 'esfera de um conceito' a sua extensão, i.e., o conjunto das coisas às quais o conceito se aplica, então Kant parece estar dizendo que para um juízo universal ser verdadeiro a extensão do termo sujeito precisa estar contida na extensão do termo predicado; e que para um juízo particular ser verdadeiro as duas extensões precisam ter algum elemento comum. Ele parece também supor que essas extensões não são vazias. Pois, se pudesse haver um termo sujeito vazio, o juízo universal com esse termo sujeito seria supostamente verdadeiro (o conjunto vazio estando contido em qualquer conjunto), mas o juízo particular correspondente não - violando a lei de inferência por subalternação, que ele explicitamente endossa. Alguém poderia sugerir - lendo 'parte' como 'subconjunto' - que a condição que Kant tinha em mente ao formular as condições de verdade dos juízos afirmativos particulares era que algum subconjunto da extensão do sujeito precisa estar contido na extensão do predicado. Isso tornaria as proposições afirmativas particulares com termos sujeitos vazios verdadeiras; mas tornaria também qualquer outra proposição afirmativa

\footnotetext{
${ }^{2}$ Ar. $2415-20$
}

Manuscrito - Rev. Int. Fil., Campinas, v. 35, n. 1, p. 99-113, jan.-jun. 2012. 
particular verdadeira - pelo fato, mais uma vez, de que o conjunto vazio está contido em qualquer conjunto.

Alguém poderia objetar que a famosa tese kantiana que “'ser' não é um predicado real” tornaria inadequado falar de proposições da forma Existe um F em conexão com o pensamento Kantiano. Mas isso seria um equívoco. O próprio Kant afirma (A598/B626) que "todas as proposições existenciais são sintéticas". Claramente, portanto, a tese de que ao dizer 'Deus é' nós não acrescentamos nenhum predicado ao sujeito, mas apenas "o colocamos em si mesmo com todos os seus predicados" (A599/B627) não implicava para Kant na inexistência de proposições ou juízos existenciais. É de fato difícil ver que sentido poderia haver em discutir se é possível provar a existência de Deus se não houvesse uma proposição ou juízo expresso pela sentença 'Deus existe'. Seja como for, a conclusão parcial

Para qualquer conceito $G$ existe um conceito $F$ tal que a proposição Algum Fé G é cognoscível a priori,

que pode ser derivada na ausência de P5, parece suficientemente paradoxal por si só. Certamente Kant não aceitaria a existência de um conceito $F$ tal que, por exemplo, a proposição Algum Fé filósofo é cognoscível a priori.

Quanto a P6, sua atribuição a Kant baseia-se mais na sua plausibilidade intrínseca do que em evidências textuais diretas. P6 não afirma que para qualquer conceito que alguém possua há um outro conceito em seu repertório que contenha o primeiro, mas apenas que um tal conceito sempre existe. Em realidade, para qualquer conceito $G$ podemos definir conceitos $\mathrm{F}$ que o contenham, pondo $F=\operatorname{df} G \& H$, onde $H$ é um conceito qualquer distinto de $G$, ou $F=\operatorname{df} G \& p$, onde $p$ é uma proposição qualquer. Alguém poderia objetar que há um certo "platonismo" a respeito de conceitos embutido em P6, o que poderia ir de encontro à concepção aparentemente mais psicológica dos conceitos em Kant. Mas esse é um problema fácil de ser contornado, pois não faria muita diferença se P6 afirmasse apenas que para qualquer conceito 
$G$ é possivel construir um conceito $F$ que o contenha. De qualquer modo, como apontei na seção I, o paradoxo em questão não necessita, a rigor, de toda a generalidade de P6. Qualquer conceito não-transcendental $G$ que admitamos estar contido em um outro é suficiente para gerar a dificuldade, pois podemos assumir com segurança que Kant não quereria afirmar a aprioricidade da realidade objetiva de $G$.

\section{III}

O problema acima parece ter duas vias razoáveis de solução: negar P3, isto é, negar a validade da regra de inferência por subalternação, ou negar P5, i.e., negar a força existencial da forma afirmativa particular. Uma outra idéia que pode surgir naturalmente é que os juízos analíticos para Kant falam, na verdade, de conceitos. Assim, o que ele quereria dizer com Todo corpo é extenso é algo como $O$ conceito extensão está contido no conceito corpo, o que é compatível com a vacuidade dos respectivos conceitos. Mas embora algumas formulações de Kant possam sugerir essa interpretação, ela é certamente equivocada. Kant em momento algum sugere que sentenças afirmativas universais sintéticas tenham uma forma lógica distinta das analíticas. Mas essa solução de fato implica isso, uma vez que, de outro modo, não haveria verdades afirmativas universais sintéticas, o que é absurdo.

Quanto às duas alternativas acima, negar P5 implica atribuir a Kant uma distinção meinongiana entre existência e subsistência, entre existir e ser algo, o que parece extremamente implausível. Ao menos eu não estou ciente de nenhuma evidência textual que sugira que Kant tinha alguma distinção desse tipo em mente.

Resta-nos, portanto, a solução "moderna", isto é, negar P3. A dificuldade aqui, porém, é que isso contradiz a crença kantiana no caráter definitivo da lógica aristotélica. Além da passagem da CRP já mencionada, na Lógica lemos que a mesma encontra-se numa situação “estável”, e que não será mais alterada. De fato, não se encontra nem na CRP, nem na Lógica, nem no texto pé-crítico "A falsa sutileza das 
quatro figuras silogísticas" nenhuma declaração de tom revisionista com respeito às regras de inferência formuladas por Aristóteles. Contudo apresentarei agora o que me parece ser uma forte evidência em favor da tese de que essa solução está implícita em Kant.

Se há algum lugar da CRP onde deveríamos esperar ver o problema acima abordado, esse lugar é a discussão da prova ontológica da existência de Deus contida no Capítulo III, do Livro Segundo da Dialética Transcendental. E, de fato, em sua discussão da prova ontológica, Kant diz:

(...) [A] necessidade incondicionada dos juízos não é uma necessidade absoluta das coisas. Porque a necessidade absoluta do juízo é só uma necessidade condicionada da coisa ou do predicado do juízo. A proposição acabada de citar [um triângulo tem três ângulos] não dizia que três ângulos são absolutamente necessários mas que, posta a condição de existir um triângulo (de ser dado), também (nele) há necessariamente três ângulos. (CRP, A594, B622, grifo meu)

Nessa passagem, Kant parece afirmar que Um triângulo tem três ângulos - que ele está claramente tomando como uma proposição universal - é o que chamaríamos hoje de um condicional universalmente quantificado, isto é, algo da forma $\forall x(F x \rightarrow G x)$. (O condicional em questão parece ser o condicional estrito e não o material, mas isso não é relevante nesse contexto). A proposição afirmaria apenas que se um triângulo existe (é dado), então ele possui necessariamente três ângulos. Note que a referência anafórica do pronome 'ele' impede que nós interpretemos Kant como afirmando que se (existe um triângulo), então (existem três ângulos).

Juízos dessa forma não são, contudo, oficialmente reconhecidos por Kant. Um juízo da forma 'Se algo é F, então ele é G' não poderia ser nem categórico, nem hipotético, nem disjuntivo, sendo essas as únicas três formas relevantes para o presente propósito que Kant reconhece, seja na Lógica, seja na própria CRP. Os juízos em questão não podem ser categóricos da forma afirmativa universal por estarem em clara contradição com a relação de subordinação e a regra 
de conversão por acidente; tampouco podem ser hipotéticos, na medida em que um juízo hipotético "consiste de dois juízos, que estão conectados a título de razão e conseqüência" (Log. \#25). Alguém poderia ainda pensar que os juízos em questão seriam classificados por Kant como disjuntivos, pois ele dá como exemplo de juízo disjuntivo 'O sábio é possuidor ou bem de um saber histórico ou bem de um saber racional', sendo que nós sabemos que 'Tudo é tal que, se for um triângulo, então tem três ângulos' é equivalente a 'Tudo é tal que, ou bem não é um triângulo ou bem tem três ângulos'. No entanto, essa equivalência funciona sob a suposição de que o 'ou' é lido inclusivamente, enquanto que Kant afirma na Lógica, \#29, que num juízo disjuntivo o 'ou' deve ser lido exclusivamente. $\mathrm{O}$ 'ou' inclusivo pode, nós sabemos, ser definido em termos do 'ou' exclusivo com o auxílio, por exemplo, da conjunção. Escrevendo 'ou' para o sentido exclusivo, temos que ' $p$ ou $q$ ' é equivalente a ' $(p$ ou $q)$ ou $(p \& q)$ '. Mas evidentemente essa definição também extrapola os limites das formas lógicas reconhecidas por Kant.

Por fim, mesmo que a lógica kantiana admitisse juízos da forma em questão, isto é, condicionais universalmente quantificados, como algo adicional, os juízos categóricos universais continuariam a gerar o problema com o qual iniciamos. Em outras palavras, a passagem acima precisa ser vista como uma reinterpretação da forma categórica afirmativa universal.

Essa parece ser claramente a melhor solução para o problema inicial. Estou, contudo, plenamente ciente da estranheza que ela pode causar. A conclusão a que essa solução conduz é simplesmente que há uma inconsistência na base da filosofia teórica de Kant. Por um lado, em alguns de seus principais escritos lógicos e em pronunciamentos sobre lógica, Kant não hesita em declarar sua adesão à silogística. Por outro lado, sua teoria dos juízos analíticos parece exigir uma interpretação da forma categórica afirmativa universal incompatível com a silogística, interpretação essa que antecipa o posterior desenvolvimento da lógica e que parece tornar-se explícita no contexto 
da discussão da prova ontológica, mas aparentemente sem que Kant notasse a discrepância.

É importante não confundir a reinterpretação da forma $A$, que afirmamos ter sido realizada por Kant, com a célebre tese que 'ser' não é um "predicado real". Esta é amplamente reconhecida como uma precursora da concepção de Frege e Russell da quantificação como predicação de segunda-ordem. ${ }^{3}$ Grosso modo, nessa visão, dizer que há Fs é afirmar do conceito $F$ que ele não é vazio. Similarmente, dizer que Deus existe seria, aproximadamente, dizer que o conceito Deus (i.e. o conceito o ser sumamente perfeito) não é vazio. Mas essa concepção é perfeitamente compatível com a preservação da força existencial da forma $A$. Na interpretação tradicional, 'Todo $A$ é $B$ ' significa algo como '(Se algo é $A$, então ele é $B$ ) e há algum $A$ '. Ela deixa, portanto, em aberto como 'Há algum $A$ ' deve ser interpretado.

A distinção entre esses dois pontos pode ser vista também com base em uma análise da passagem sobre a prova ontológica. A crítica de Kant à prova ontológica parece poder ser dividida em duas partes. $\mathrm{Na}$ primeira (A592/B620 a A596/B624) ele apela para o que denomina "considerações gerais com as quais qualquer um precisa concordar". Nessa parte, Kant afirma que, influenciados pela "necessidade incondicionada de juízos", i.e., pela necessidade de um juízo como 'Todo triângulo tem três lados', alguns supõem que o simples fato de formar um conceito que "inclui a existência no escopo do seu significado" justificaria a afirmação da existência de um objeto caindo sob o conceito. Seu ponto aqui é, simplesmente, que do fato de que, necessariamente, todo $F$ existente é existente, não se segue que exista um $F$ existente. É nessa primeira parte da discussão que está implícita a reinterpretação da forma $A$. É importante observar que, nessa altura, nada ainda foi dito sobre a "realidade" do predicado de existência. Com efeito, Kant admite, ainda que talvez apenas for the sake of argument, que nós podemos formar conceitos no escopo dos quais a existência está

\footnotetext{
${ }^{3}$ Ver, por exemplo, Wood (2009).
}

Manuscrito - Rev. Int. Fil., Campinas, v. 35, n. 1, p. 99-113, jan.-jun. 2012. 
incluída. Mas é simplesmente um ponto geral de lógica (não-aristotélica!), que daí não se segue que algo caia sob o conceito.

É apenas na segunda parte do argumento que Kant introduz a idéia de que 'ser' não é um predicado real. Nessa segunda parte, Kant parece estar preocupado em responder a alguém que insista em sustentar o argumento ontológico, a despeito das "considerações gerais" precedentes. A passagem suscita grandes dificuldades interpretativas e é de se perguntar se a primeira parte não é refutação suficiente. Mas felizmente nós não precisamos entrar nessa discussão aqui, pois são precisamente essas "considerações gerais", cuja essência é a reinterpretação da forma $A$, que são relevantes para nós. $\mathrm{O}$ fato de que essas considerações lógicas gerais contrariam a silogística me parece ser pouco apreciado. Com efeito, como já dissemos, o próprio Kant parece não ter se dado conta de que estava indo contra uma lei do sistema de lógica cuja correção ele afirmara nas primeiras páginas da mesma obra. Mas, seja como for, um ponto que me parece ser ainda menos apreciado é que a rejeição da força existencial da forma $A$ (e também da forma $E$ ) é necessária para evitar, de modo plausível, o colapso das teses sobre analiticidade e aprioricidade que formam a base a filosofia teórica de Kant.

Necessária, sim; mas não suficiente. Há um problema residual no fato de que, na lógica clássica de primeira-ordem, $\forall x \varphi x$ implica $\exists x$ $\varphi x$. Assim, em particular, $\forall x(F x \rightarrow G x)$ implica $\exists x(F x \rightarrow G x)$. Desse modo, ainda haveria proposições existenciais cognoscíveis a priori, como, por exemplo, 'Existe algo tal que, se é um corpo, então é extenso'. Mas pode-se sustentar que a possibilidade de conhecer de modo a priori a realidade objetiva do conceito extenso, se corpo não é menos contrária ao espírito da filosofia de Kant do que no caso dos conceitos de extensão e corporeidade. ${ }^{4}$

${ }^{4}$ Essa tese pode ser questionada. Talvez a proposição 'Existe ao menos um objeto’ seja uma proposição sintética a priori. Nesse caso, se $\forall x(F x \rightarrow G x)$ é analítica, $\exists x(F x \rightarrow G x)$, que se segue logicamente dela em conjunção com 'Existe ao menos um objeto', poderia ser considerada como sendo também 
Do ponto de vista semântico, o problema deriva do fato de que o domínio dos modelos das linguagens de primeira-ordem é sempre um conjunto não-vazio. É por essa razão que o que quer que valha para todos, vale também para algum. Em particular, na lógica clássica de primeira-ordem com identidade, como temos o axioma $\forall x x=x$, a proposição $\exists x x=x$ é um teorema. As lógicas nas quais essa restrição a conjuntos não-vazios não é imposta são chamadas de inclusivas ou universalmente livres. Podemos concluir que é uma lógica desse tipo que fornece a melhor base para uma reconstrução do sistema kantiano que seja consistente com as teses centrais sobre aprioricidade e analiticidade. Assim, a lógica mais adequada ao sistema kantiano, longe de ser aristotélica, não é nem mesmo clássica.

sintética a priori. É difícil encontrar em Kant evidências decisivas quanto a esse ponto. Em todo caso, parece claro que Kant negaria que uma proposição existencial possa ser conhecida exclusivamente com base na lógica geral, i.e., sem o auxílio da intuição, pura ou empírica. Mas é precisamente isso que a adoção da lógica clássica propiciaria.

Manuscrito - Rev. Int. Fil., Campinas, v. 35, n. 1, p. 99-113, jan.jun. 2012. 


\section{Referências bibliográficas:}

ARISTOTLE. Categories, On Interpretation, Prior Analytics. Transl. by H. P. Cooke \& H. Tredennick, Loeb Classical Library, Harvard Univeristy Press, 1983.

BAR-HILLEL, Y. Logic, Methodology and Philosophy of Science. NorthHolland Publishing Company, 1965.

CHURCH, A. "The History of the Question of Existential Import of Categorical Propositions”. In Y. Bar-Hillel (ed.) (1965), pp. $417-$ 424.

KANT, I. Kritik der Reinen Vernunft. Hamburg: R. Schmidt (Ed.), $2^{\mathrm{a}}$ ed. Rev., 1930. Trad. de M. P. dos Santos e A. F. Mourujão. Lisboa: Fundação Colouste Gulbenkian, 1997.

- Prolegomena zu einer jeden künftigen Metaphysik die als Wisseschaft widr auftreten. Riga: Johan Friedrich Hartknoch, 1783. Trad. de G. Hatfield. Cambridge: CUP, 1997.

Immanuel Kants Logik ein Handbuch zu Vorlesungen. Texto estabelecido por Gottlob Benjamin Jäsche, Königsberg: Friedrich Nicolovius, 1800. Trad. de Guido Antônio de Almeida, Rio de Janeiro: Tempo Brasileiro, 1992.

PARSONS, T. “The Traditional Square of Opposition”. In The Stanford Encyclopedia of Philosophy. E. Zalta (ed.), 2006.

SANTOS, P. "Força Existencial e Formas Categóricas na Silogística de Aristóteles”. Integração, XIII, 50, pp. 283-290, 2007.

WOOD, A. Kant's rational theology. Cornell: Cornell University Press, 2009. 